Comentário

\title{
Commentary
}

\section{A importância da ciência Educação Física na preparação operacional de militares: premissas da Academia Militar dos Estados Unidos - West Point}

\section{The Importance of Physical Education Science for Operational Preparation of Military: Assumptions of the United States Military Academy - West Point}

Inaldo Pereira dos Santos ${ }^{\S 1}$ Esp; Luciano Vieira ${ }^{2}$ MS; Lilian Martins ${ }^{2,3} \mathrm{PhD}$

Recebido em: 30 de junho de 2018. Aceito em: 30 de junho de 2018

Publicado online em: 13 de julho de 2018.

\section{Resumo}

Introdução: A Educação Física teve suas origens no treinamento físico militar. Nos dias atuais, a preparação física continua sendo uma das facetas mais importantes da operacionalidade militar.

Objetivo: Descrever a importância do treinamento físico na preparação profissional do militar, por meio da observação dos objetivos e práticas educacionais do Departamento de Educação Física (DEF) da Academia de West Point (AWP) dos Estados Unidos da América.

Conclusão: O DPE da AWP atinge o objetivo de preparar os cadetes para as situações que serão vividas em ambiente de guerra e faz isso com excelência, utilizando-se da Educação Física como ciência.

Palavras-chave: treinamento físico, militares, métodos.

\section{Abstract}

Introduction: Physical Education had its origins in military physical training. Nowadays, physical preparation continues to be one of the most important facets of military operationality.

Objective: To describe the importance of physical training for the professional preparation of the military, by observing the objectives and educational practices of the Department of Physical Education (DPE) of the West Point Academy (WPA) of the United States of America.

Conclusion: WPA's DPE achieves the goal of preparing the cadets for situations that will be experienced in war environment and does so with excellence, using Physical Education sciences.

Keywords: physical training, military personnel, methods.

\section{Pontos-Chave Destaque}

- Educação Física e preparação física militar: origens e relações.

- A importância da Educação

Física no contexto militar: ontem e hoje.

- Atingindo objetivos profissionais por meio da Educação Física.

\section{Keypoints}

- Physical Education and military physical preparation: origins and relationships.

- The importance of physical education in the military context: yesterday and today. - Achieving professional goals through Physical Education.

\footnotetext{
$\S$ Autor correspondente: Inaldo Pereira dos Santos - e-mail: maj.inaldo97@gmail.com Afiliações: ${ }^{1}$ Escola de Educação Física do Exército (EsEFEx); ${ }^{2}$ Instituto de Pesquisa da Capacitação Física do Exército (IPCFEx); ${ }^{3}$ Centro de Capacitação Físic do Exército (CCFEx).
} 


\section{A importância da ciência Educação Física na preparação operacional de militares: premissas da Academia Militar dos Estados Unidos - West Point}

As origens do treinamento físico remontam aos primórdios da civilização humana, tendo surgido da necessidade de preparação dos homens para a guerra(1). Desde os mais remotos registros, os povos se organizavam para conquistar novas fronteiras ou para defender as já existentes. O treinamento físico existia muito antes da civilização grega, no entanto, a literatura indica que seus exércitos refinaram a preparação para a guerra, sistematizando o treinamento físico de seus soldados(1). Nesse ponto da história estão as origens da Educação Física, cujo conhecimento científico evoluiu ao longo das eras tornando-se uma ciência de grande relevância e complexa devido sua multidisciplinariedade.

$\mathrm{Na}$ atualidade, a importância da Educação Física permanece, pois, trata-se da base científica para a preparação de soldados ao redor de todo o mundo $(1,2)$.

Nesse contexto, o Exército Brasileiro precedeu os estudos da educação física no Brasil, e hoje, continua na batalha para se manter na ponta em relação a atividade física voltada para a saúde e a operacionalidade da tropa, por meio de seus órgãos de ensino e pesquisa na área.

Um dos exércitos mais proeminentes no mundo, devido à sua alta competência e sucesso na maior parte das missões, é o Exército dos Estados Unidos da América (EUA). Historicamente aliado do Brasil, faz parte do seu grupo Nações Amigas, com as quais são realizados diversos tipos de intercâmbios profissionais militares, com destaque para a área da educação. Observa-se que o Exército Brasileiro possui elevado conceito perante o Exército Americano, o que motiva a continuidade dos intercâmbios.

Recentemente, em dezembro de 2017, o Comando do Exército, por meio do Departamento de Educação e Cultura do Exército (DECEx) enviou uma missão de intercâmbio da Escola de Educação Física do Exército (EsEFEx) ao Departamento de Educação Física da Academia Militar dos Estados Unidos, em West Point, NY. Na oportunidade, foi possível observar a importância do treinamento físico na formação do oficial de carreira do Exército Americano, bem como de que maneira, efetivamente, as atividades físicas ajudam a transformar civis de ambos os sexos, em guerreiros que irão viver todos os tipos de vicissitudes em combate.

\section{A Academia de West Point (AWP)}

Para entender o funcionamento do Departamento de Educação Física (DEF), é necessário compreender um pouco a própria Academia Militar dos Estados Unidos ou, simplesmente, Academia de West Point (AWP). Esta foi criada em 1803 por Thomas Jefferson (principal autor da Declaração da Independência e $3^{\circ}$ Presidente Americano, no período de 1801 a 1809).

Desde a sua criação, a AWP promove excelente formação dos cadetes do Exército Americano, que se deve à perfeita combinação entre o ensino militar, o ensino acadêmico e a preparação física.

Inicialmente, havia apenas homens nas fileiras de soldados americanos. As mulheres foram aceitas em West Point a partir de 1976. Nos dias atuais, a AWP conta com 4.400 cadetes, dos quais $25 \%$ correspondem ao segmento feminino, distribuídos pelos 4 anos de formação.

Os cadetes ingressam na AWP por meio de concurso público, como vestibular, tipo Exame Nacional do Ensino Médio (ENEM) ou por meio da Escola Preparatória de Cadetes. As idades dos cadetes variam entre 17 e 21 anos.

O ensino acadêmico é o elo mais forte da corrente em West Point, seguido do ensino militar e da preparação física. West Point oferece 40 cursos de graduação, todos similares aos ofertados pelas Instituições Civis de Ensino Superior dos Estados Unidos. Entre as possíveis graduações de West Point, que os cadetes podem optar, está o curso de Educação Física.

\section{O Departamento de Educação Física (DEF)}

$\mathrm{O}$ DEF tem como principais missões: planejar, preparar, executar e assessorar o 
Comando da AWP, no que diz respeito a todas as atividades físicas realizadas pelos cadetes, além de graduar aqueles que optarem por cursar Educação Física.

O corpo docente do Departamento é composto por civis e militares. Os civis possuem doutorado e pós-doutorado e são admitidos por concurso público. Os militares são todos de carreira e graduados em Educação Física, por West Point.

O DEF possui inúmeras instalações desportivas, com estrutura equiparada à do Centro de Capacitação Física do Exército (CCFEx). O principal objetivo do Departamento é desenvolver ou aprimorar a agressividade e a liderança nos cadetes de ambos os sexos.

\section{O treinamento físico militar na formação do oficial militar americano}

O treinamento físico militar, em West Point, visa a construir e consolidar atitudes comportamentais úteis em cenários de conflitos armados, tais como: coragem, resiliência, "manage fear \& stress" (gerenciamento do medo e do estresse), autoconfiança e probidade.

No intuito de desenvolver a agressividade, são ministradas aos cadetes do primeiro ano (Fourth-Class cadets) as disciplinas de boxe e jiu-jítsu, tanto para os homens, quanto para as mulheres.

Os Cadetes têm que apresentar resultados físicos (psicomotores) e de liderança (atitudes comportamentais) satisfatórios para conseguirem concluir os cursos em West Point. A fim de atingir tais objetivos, a estratégia traçada pelo DEF foi distribuir 10 (dez) disciplinas (courses) ao longo dos 4 anos de formação. As disciplinas que compõem o "core" curricular elaborado pelo DFE possuem correspondentes na EsEFEx. São elas: Desenvolvimento de Aptidão Física Militar (Army Fitness Development, que corresponde à disciplina Treinamento Físico Militar: TFM); Boxe (Boxing); Práticas de Combate (Combat Applications, que corresponde à disciplina Lutas,); Natação Utilitária (Survival Swimming); e Ginástica Militar (Military Movement). Em todas as disciplinas, as ideiasforça são: desenvolver o espírito guerreiro (warrior spirit), contribuir para aumentar a autoconfiança, melhorar o controle do medo e do estresse, desenvolver a agressividade e a coragem.

\section{Conclusão}

As ideias iniciais, quanto à preparação física para o combate, dos espartanos consideravam as qualidades força, mobilidade, velocidade e resistência como chave para o sucesso tanto no campo de batalha quanto no estádio e, além disso, havia a noção de que exercícios de ginástica estavam relacionados à saúde(3). Observa-se que tais preceitos permanecem na preparação profissional do militar até os dias atuais.

O DPE da AWP atinge o objetivo de preparar os cadetes para as situações que serão vividas em ambiente de guerra e faz isso com excelência, utilizando-se da Educação Física como ciência capaz de produzir no ser humano as grandes transformações, necessárias para superar e vencer todas as dificuldades decorrentes de um conflito armado.

"Quanto mais você sua na paz, menos você sangra na guerra"

Sun $\mathrm{Tzu}(4)$

\section{Declaração de financiamento}

Financiamento do Exército Brasileiro.

\section{Referências}

1. Oldfield EAL. History Of The Army Physical Training Corps. Aldershot, UK: Gale \& Polden Ltd; 1955. 169 p.

2. Spivey N. The Ancient Olympics. New York: OUP Oxford; 2012. 177 p.

3. East WB. A Historical Review and Analysis of Army Physical Readiness Training and Assessment: [Online] Defense Technical Information Center, 2013 Mar [Accessed: 12th July 2018]. Available from: doi:10.21236/ADA622014 [Accessed: 12th July 2018]

4. Tzu S. The Art of War. CreateSpace Independent Publishing Platform; 2016. $102 \mathrm{p}$. 